\title{
Drug treatment programmes in prison: longitudinal outcome evaluation, policy development and planning interventions
}

\author{
Julian Pugh and Catherine M Comiskey
}

\section{Abstract}

Aims: The aim of this research is to evaluate a seven week abstinence-based drug treatment programme and to use this to assist policy makers in the planning and provision of future programmes.

Methods: Design: Seventy-nine clients were interviewed at two stages. Stage I, prior to the treatment programme, stage II, immediately after the treatment programme. A selected group of 20 clients were followed-up and interviewed at stage III, up to 24 months after the treatment programme.

Setting: All clients were prisoners at Mountjoy Prison, Dublin Ireland.

Participants: Seventy-nine male prisoners were recruited. A sample of 20 of the original cohort of 79 was selected using a snowball sampling method approximately 24 months following treatment. This latter sample of $\mathbf{2 0}$ clients consisted of eight prisoners who had re-offended and returned to prison, three prisoners who were still in prison serving their original sentence and nine prisoners who were out of prison. These 20 also participated in a more detailed quantitative and qualitative survey.

Measurements: In order to measure prisoner's criminogenic attitudes and needs the Crime Pics II instrument was used. This is a semantic differential scale which measures attitudes toward offending behaviour. It includes a problem checklist which can be used to measure change over time.

Results: An $82 \%$ follow-up rate was achieved on the original group of 79 clients, similarly a follow-up rate of $100 \%$ was also achieved for the selected group of 20 clients who were interviewed three times. Regardless of category of client, findings demonstrate an improvement over time for the outcome variables, general attitude to offending, anticipation of re-offending and perception of current life problems. However, the study failed to demonstrate any significant change for the outcome variables victim hurt denial and evaluation of crime as worthwhile.

*Julian Pugh, M.Sc, BA, COSW, SRN, RMN. Co-ordinator Drug Treatment Services (Prisons), Health Service Executive, Mill Lane, Palmerstown, Dublin 20, Ireland.

Catherine M Comiskey, BA (Mod), M.Sc, Ph.D. Mathematics Department, National University of Ireland, Maynooth, Co Kildare, Ireland.

${ }^{*}$ Correspondence

SUBMITTED: JANUARY 4, 2005. ACCEPTED: MARCH 30, 2006.
Conclusions: These results were short lived for many prisoners, who failed to sustain the gains made. Interviews with the cohort of $\mathbf{2 0}$ who underwent stage III interviews possibly suggest that those clients who did not receive continuity of treatment post programme, in terms of case management and structured treatment, did not fare as well as those who did.

Key words: Drug use; Treatment; Prison; Outcome evaluation; Crime; Group work; Offending behaviour; Case management.

\section{Introduction}

The aim of this research was to evaluate the outcomes of prisoners who underwent the drug treatment programme in the medical unit, Mountjoy Prison in Dublin, Ireland. To date there have been some small-scale evaluations of this programme..$^{1,2}$ However as yet, no large-scale drug treatment evaluation has been conducted. This research represents the first attempt to address this gap in the Irish prison service's evaluation literature. This is also the first longitudinal study of its kind where prisoners were evaluated over a period of two years.

Marsden et $\mathrm{a}^{3}$ and Gossop et al ${ }^{4}$ have highlighted the need to develop valid and reliable instruments to measure treatment outcome for problems of substance use. Indeed, Gossop et al ${ }^{5}$ noted a consistent reduction in criminal activity following treatment, although treatment programmes in the United Kingdom seldom specifically target these behaviours.

\section{Research findings}

International research on prison drug treatment programmes has highlighted the need for programmes to be relevant to their situation and to have continuity of care prior to and following release. Inciardi et $\mathrm{al}^{6}$ describe treatment options as including therapeutic communities, psycho-educational programmes and drug awareness programmes.

Turnbull and McSweeney in their literature review of three surveys of drug treatment in European countries highlight the need to develop particular strategies for prison drug treatment noting the specific needs of this population in terms of throughcare, which is a notoriously difficult area to address. . $^{8,9,10}$

Turnbull and Mc Sweeney ${ }^{7}$ comment upon the effectiveness of prison-based therapeutic communities, particularly those that are followed-up with aftercare. This is supported by Inciardi et $\mathrm{al}^{6}{ }^{6}$ thus challenging earlier views expressed by commentators such as Hough, ${ }^{11}$ who state that better outcome is achieved the longer people remain in residential treatment.

Canadian research emphasises, the need to focus upon incre- 
mental change in the development of ongoing treatment programmes, the inherent inferential problems associated with selection bias, its impact upon the selection of more motivated clients and the tendency of higher risk prisoners to drop out and consequently to fail to make use of transitional services. ${ }^{12}$ Porpino et $\mathrm{al}^{12}$ have suggested that continuity of treatment provision is important, particularly following release and that this is linked to re-offending rates. This has implications for the construction of effective case management systems and the "layering of programmes over time in order to address criminogenic need". They have noted that empirical results of evaluation show a positive association between post-release success and participation in community programming.

The CDATE project undertook a meta- analytic examination of over 1500 evaluation research studies on the effectiveness of treatment programmes, including drug users and non-drug users between 1968 and $1996 .{ }^{13}$ They note that prisonbased TCs have dropout rates averaging $50 \%$ per annum compared to $70-90 \%$ in the community based TCs. Furthermore the authors noted that the programmes displayed significant results in reducing recidivism.

Their research also documented that there were negligible differences in outcomes for short-term TC programmes when compared to ones over six months in duration. This presumes continuity of treatment via transitional care planning and community treatment and raises the question of whether continuity of treatment requires that treatment be administered in a residential TC or whether structured day support and treatment would fulfil the requirement for programme effectiveness? The latter is the case in the Mountjoy programme.

Taxman and Bouffard ${ }^{14}$ highlight many research contributions which demonstrate the effectiveness of the therapeutic community model in terms of addressing offending behaviour and substance abuse. They also comment on the lack of description of such models and the type of interventions contained within them. These authors proffer a list of operational definitions when undertaking structured observations of TCs. These in combination with what Inciardi et al ${ }^{6}$ regards as the essential components of drug treatment programmes would enhance process evaluation of such group interventions and by so doing improve their integrity. However, the operational demands of maintaining treatment programmes make such a task onerous. In summary there is a consensus, which is highlighted by Ramsay, ${ }^{15}$ that drug treatment programmes in prison can be effective if they are based on the needs of prisoners, are of sufficient length and quality and there is continuity of aftercare in prison and in the community.

\section{The Mountjoy prison drug treatment programme}

On the basis of research evidence which supports the use of therapeutic programmes for the treatment of drug users, a decision was made to establish a programme for prisoners in Mountjoy Prison. The Probation and Welfare Service established the programme in July 1996, with the approval of the Minister for Justice. The programme accepts nine prisoners, every seven weeks and takes place in a designated drug free wing of the Medical Unit. Prisoners may elect to undergo a ten day methadone detoxification period prior to commencement of the six-week therapeutic phase. Group selection is dependent upon the use of two criteria. Prisoners must not have more than two years of their sentence to serve or have

\section{Box 1: Crime Pies II}

Scale

$\begin{array}{ll}\text { alpha } & \text { Test-retest } \\ \text { Coefficient } & \text { Correlation }\end{array}$

G - General attitude to offending

0.76

0.63

A - Anticipation of re-offending

0.75

0.58

V - Victim hurt denial

0.73

0.59

E - Evaluation of crime as worthwhile

0.55

0.56

$P$ - Perception of current life problems

0.83

0.55

a Circuit Court sentence review date within the following two years. Prisoners stand a better chance of being selected if they have displayed some level of motivation within the prison system by making use of available facilities. Opportunities for prisoners exist in terms of the provision of cognitive behavioural therapy (CBT) worksheets which prisoners can complete in their cells. Liese and Franz ${ }^{16}$ state that the benefits of relevant CBT homework assignments allows individuals to practice new skills and examine faulty beliefs and if jointly constructed with the worker they promote a feeling of control and responsibility. Regular drug awareness courses are provided. These introduce prisoners to the concepts of drug treatment and group work.

\section{Methodology}

Seventy-nine male prisoners were recruited to the study. The programme members were selected independently, from a constant waiting list of approximately 40 prisoners. Selection was by a senior probation officer and a chief prison officer on the basis of displayed motivation while in prison. All clients were interviewed immediately prior to programme commencement and immediately after completion. Subsequently twenty of the initial cohort were selected by snowball sampling approximately 24 months later and they completed a further third interview. In other words the location of those nominated was provided by clients already known to the service. There was no reason to assume that those who were nominated in this way were in anyway similar, in terms of outcome measures, to those who nominated them. These 20 clients were categorised as category one, two or three clients, where category one were those who were returned re-offenders, category two were still in prison and category three clients were out of prison. These 20 also participated in a more detailed quantitative and qualitative survey, the results of which are not reported here. Those who were not selected to complete all three interviews were categorised as category zero clients.

In order to measure criminogenic attitudes and needs the Crime Pics II instrument was used to assess changes in attitude prior to and after the completion of the programme. ${ }^{17}$ The Crime Pics II is a semantic differential scale measuring attitudes toward offending behaviour and includes a problem checklist. It can be used to measure change. In the case of this study it provided a standardised instrument to enhance an assessment process, to fine tune some of the group work inputs, addressing specific prisoner difficulties and to elicit 


\section{Table 1: Deseriptive statistics for all prisoners}

$\begin{array}{ll}\text { Variable and stage } & \text { N } \\ \text { General attitude to offending, Stage } 1 & 79 \\ \text { General attitude to offending, Stage } 2 & 64 \\ \text { General attitude to offending, Stage } 3 & 20 \\ \text { Anticipation of re-offending, Stage } 1 & 79 \\ \text { Anticipation of re-offending, Stage } 2 & 64 \\ \text { Anticipation of re-offending, Stage 3 } & 20 \\ \text { Victim hurt denial, Stage 1 } & 79 \\ \text { Victim hurt denial, Stage 2 } & 64 \\ \text { Victim hurt denial, Stage 3 } & 20 \\ \text { Evaluation of crime as worthwhile, Stage } 1 & 79 \\ \text { Evaluation of crime as worthwhile, Stage } 2 & 64 \\ \text { Evaluation of crime as worthwhile, Stage } 3 & 20 \\ \text { Perception of current life problems Stage } 1 & 79 \\ \text { Perception of current life problems, Stage } 2 & 63 \\ \text { Perception of current life problems, Stage } 3 & 20\end{array}$

the potential of a focused drug treatment intervention designed to modify criminogenic beliefs and attitudes.

Crime Pics II provides reliable and valid scales with numerical measures in order to produce five profiles.

An internal alpha coefficient of 0.70 or above is usually regarded as having good internal consistency. Test - retest criterion indicate stability over time.

For the full cohort descriptive statistics only were computed for each of the five scaled variables above. More detailed inferential statistics were computed for the 20 clients who had been interviewed three times.

As the data was categorical, in order to assess if the programme effected client score, the Friedman non-parametric test for $\mathrm{k}$ related samples was performed on the 20 category one, two and three clients only and results are provided. Friedman tests the null hypothesis that $k$ related variables come from the same population. For each case, the $k$ variables are ranked from 1 to $k$. The test statistic is based on these ranks. In addition to assess if programme effected client score pre and immediately post programme, Wilcoxon matched pairs signed ranks test was performed on all variables for these category one, two and three clients. This is also a non-parametric procedure, it is used with two related variables to test the hypothesis that the two variables have the same distribution. It makes no assumptions about the shapes of the distributions of the two variables. This test takes into account information about the magnitude of differences within pairs and gives more weight to pairs that show large differences than to pairs that show small differences. Details of the results of all these tests are provided below. Finally these analyses were repeated for the category three clients only, that is those clients who were out of prison. Details of the results obtained for these nine clients are also provided.

\section{Results}

In the Mountjoy programme participants tended to be high-

$\begin{array}{lll}\text { Modal score } & \text { Mean score } & \text { Standard deviation } \\ 8 & 6.23 & 2.55 \\ 3 & 4.22 & 2.67 \\ 7 & 3.95 & 2.91 \\ 9 & 7.21 & 2.18 \\ 4 & 5.28 & 2.13 \\ 7 & 5.19 & 3.09 \\ 2 & 2.08 & 1.57 \\ 2 & 1.73 & 1.75 \\ 2 & 1.90 & 1.79 \\ 7 & 5.08 & 2.22 \\ 7 & 4.80 & 2.48 \\ 7 & 4.52 & 2.34 \\ 9 & 6.87 & 1.94 \\ 3,7 & 5.56 & 2.29 \\ 6,7 & 5.33 & 2.76\end{array}$

risk prisoners both in terms of the nature of their drug use and the seriousness of offences. Seventy-five per cent of the cohort were serving sentences in the firearms, assault and robbery category while $25 \%$ were in the theft category. Forty per cent of the cohort was serving sentences over five years, $33 \%$ between $3-5$ years and 33\% between 1-2 years. The age profile of the cohort at commencement of programme reflected $9 \%$ between 18 to 20 years, $54 \%$ between 21 to $25,26 \%$ between 26 to 30 and $11 \%$ between 31 to 38 years. Prior to programme commencement an optional methadone detoxification programme was accepted by $33 \%$ of the cohort.

A follow-up rate of $82 \%$ was achieved from stage I to stage II (pre vs post programme). By international standards a follow up rate of $70 \%$ or over is acceptable in longitudinal studies (see the NTORS reports of www.nta.nhs.uk). In addition a target of 20 clients was set to follow-up at stage III and this target was met.

For the frequencies computed for the category 0-3 clients combined, it is interesting to note that the modal score or mode (that is the most frequent observation noted in the data) decreased from stage I to stage II, illustrating an improvement. However it often increased again at stage III of the study. This can be observed in the general attitude to offending, the anticipation of re-offending and in the perception of current life problems. This pattern can also been seen in Figure 1 where we plot the mean scores.

It is also interesting to see that there is no change across the three stages in the modal score for victim hurt denial and evaluation of crime as worthwhile. The implications of these two different patterns would benefit from a more detailed sociological discussion. Especially as very similar although not identical results were also observed for the category three clients when they were analysed as an individual group. This can be seen in Table 2 . 


\begin{tabular}{lll}
\hline Table 2: Deseriptive Statistics for category three prisoners \\
(indlividuals who were back in the community at stage three)
\end{tabular}

The Friedman test performed on all variables at all three stages for the 20 category 1-3 clients only, failed to show significance. This is to be expected as it compares the results for all three stages. There was one exception to this and that was on the Friedman test for anticipation for re-offending. However it is interesting to note that as expected from the tables with the descriptive statistics the Wilcoxon analysis of the data at stages I and II for the category 1-3 clients produced significant results for the three variables general attitude to offending, anticipation of re-offending and perception of current life problems. Thus illustrating an improvement from stage I to stage II. Again as expected no significant differences between stage I and stage II were observed for the category 1-3 clients for the variables victim hurt denial and evaluation of crime as worthwhile, reinforcing the observed pattern of results noted earlier.

Looking at the category III clients - those who were out of prison, in more detail. The Friedman tests did show significant differences across the three stages for the variables general attitude to offending, anticipation of re-offending and perception of current life problems. It did not however as with the category 1-3 combined data pick up differences across the three stages for the variables victim hurt denial and evaluation of crime as worthwhile.

Looking in more detail as previously the Wilcoxon analysis of the data comparing stage I and stage II shows significant differences between results obtained at stage I and stage II for two variables only. These were the variables, general attitude to offending and anticipation of re-offending. With this category three group of clients, perception of current life problems did not change from stage I to stage II as it did with the category 1-3 combined. Also as with the category 1-3 combined no significant differences between stage I and stage II were observed for the variables, victim hurt denial

\section{Figure 1: Plot of the mean seores at interviews one, two and three}

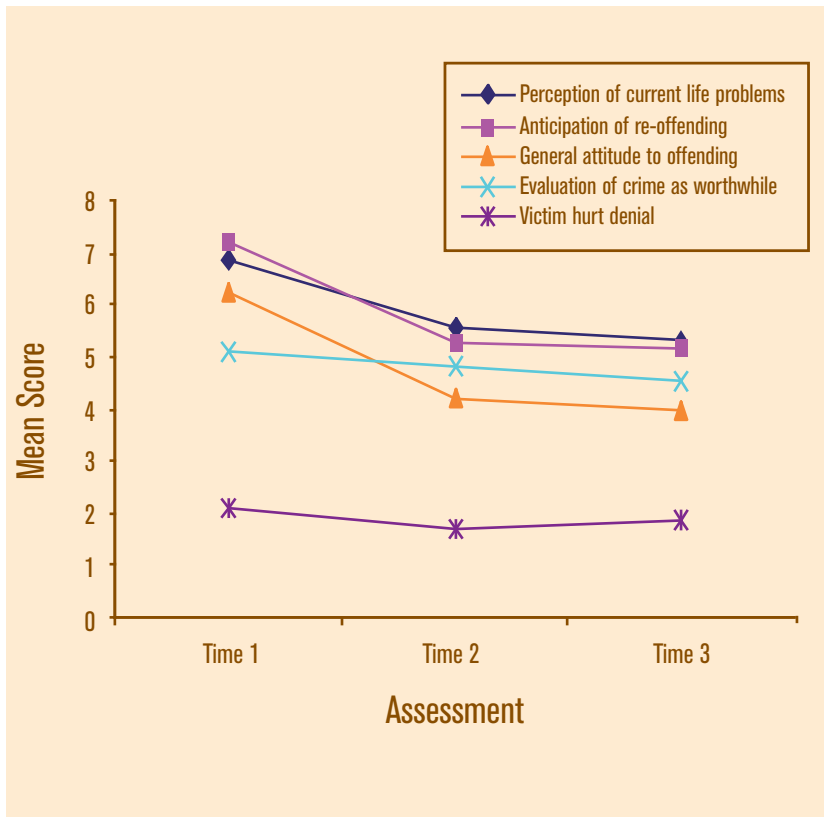

and evaluation of crime as worthwhile.

However, if we compare using the Wilcoxon test, stage II results with stage III results for the category three clients we see that significant differences were observed for the two variables, general attitude to offending, anticipation of reoffending and now also perception of current life problems is showing a difference. However, no significant differences between stage II and stage III were observed for the variables, victim hurt denial and evaluation of crime as worthwhile.

\section{Discussion}

It is necessary to consider the influence of sentencing policy on the outcome of prisoners undertaking the programme. A major incentive to complete the programme may have been the fact that a large proportion of the cohort was subject to Criminal Circuit Court sentence review.

"The review structure is a process by which a judge is able to individualise a sentence for the particular convicted sentence. It is a tool by which the judge may include in a sentence the appropriate element of punishment (retribution and deterrence) and yet also include an element of rehabilitation" (Court of Criminal Appeal, The People at the suit of the Director of Public Prosecutions v. Philip Sheedy, unreported: judgement delivered 15th October 1999 cited in DPP v. Finn, 2000).$^{18}$ This innovative practice, which had been in existence for over 100 years and put on a statutory basis by other jurisdictions, was effectively ended because it had no statutory basis and that it eroded the powers of the executive (DPP v. Finn, 2000). ${ }^{18}$ Arguably this practice, met the challenges of current social problems by stimulating offender motivation and promoting rehabilitation in a prison system with few treatment facilities. The practice also addressed "the revolving door syndrome" of prisoner management by ensuring minimum periods of incarceration. The judgement also referred to "the rather haphazard" executive process of remission because it did "not meet the penological requirement of reasonable certainty". ${ }^{18}$

Two key results emerged from the Crime Pics II analyses. 
Firstly, analyses across the three categories of client category one, two and three demonstrated surprising consistency with definite patterns emerging. Regardless of category of client or whether grouped or individual, the three variables of general attitude to offending, anticipation of re-offending and perception of current life problems continually illustrated improvements based on stage of the study and on client group. However, the two variables victim hurt denial and evaluation of crime as worthwhile failed to demonstrate any improvement from stage one to stage three. These differences require more detailed evaluation in terms of programme efficacy and the design of future interventions. However, it may be due to the fact that no sessions focused specifically on reparation or offending behaviour. In addition this pattern warrants further analysis from a criminological or sociological perspective.

A factor that might have had a potential influence upon results is that the therapeutic programme is provided by agencies with very different theoretical approaches to the management of drug misuse, a factor which might be construed as confusing to prisoners. The mix included a low threshold agency, an abstinence based agency and one which focused on family dynamics in addressing treatment issues. All agencies were familiar with each other's sessions and the cognitive behavioural approach which many shared. However, if prisoners have been well prepared for the programme and if the difference between approaches has been explained, then the potential for confusion is limited. Arguably prisoners are better prepared to select what type of community support they would prefer. To date interagency relationships have been mutually supportive and there has been a consistent commitment to the aims and objectives of the programme. There has been mutual respect for the different therapeutic models and treatment approaches used by each agency. The notion that different treatment agencies adopt different models of care reflects reality in the community, where drug users may oscillate between different agencies or opt for one particular treatment intervention rather than another. It should also be remembered that many of the agencies use similar modules of intervention and respect the models of other treatment agencies whether it be harm minimisation or abstinence based.

Inciardi, ${ }^{19}$ on the basis of reviews of the substance abuse research, outlines eighteen principles of effective treatment. To a greater or lesser extent, the staff of the drug treatment programme follows these principles. The current Mountjoy programme has operated 365 days of the year, every year, since 1996.

The efficacy of coercive drug treatments has been a bone of contention for many years. At this stage it is recognised that treatment within a prison setting is acceptable and effective when compared with individuals who elect for voluntary treatment. ${ }^{11}$ Certainly many of the Mountjoy prisoners found that treatment was a welcome opportunity to address their problems. Indeed, the benefits of the programme are often extolled by one prisoner to another. "So you're there with this stuff pouncing on top of you, about where you are at and things like that. Like after the first week I got it into my head, 'yeah, I'll give this a shot', but as you're going through it you'd be sitting in a room and they give you this topic and you talk about it, and come out of it and feel good". ${ }^{20}$

\section{Conclusion}

Analysis of the efficacy of the prison-based drug treatment programme would suggest that it has value, given the statistically significant changes brought about in three of the five dependent variables. While some bias exists in terms of the sampling and the small amounts of data, there is no reason to assume that this is significant. The authors suggest that further modules be added to the treatment programme in order to address specific offending behaviour issues and victim reparation issues. Most importantly, if the improvements noted are to be sustained, it would appear vital that a model to provide continuity of care and case management be provided beyond the treatment programme. In conclusion there is a need for further research and empirical action within the Irish prison and health services into the provision of care co-ordination and case management. The way forward has already been mapped. ${ }^{21}$

\section{Acknowledgements}

Many thanks to all the prisoners who co-operated with this research. Many thanks to the staff in Mountjoy Prison who have all pulled together with the Probation and Welfare Service, Ana Liffey Project, Coolmine Therapeutic Community and the Youth Action Project Ballymun in maintaining the continuity of the programme.

\section{Declaration of interest: None}

References

1. Crowley D. The drug detox unit at Mountjoy Prison: a review. J Health Gain. 1999; $3,(2)$

2. Foley A. Prison-Based Drug Treatment Programmes; what works. MSc dissertation. University College Dublin; Ireland, 2001.

3. Marsden J et al. The Maudsley Addiction Profile (MAP): A brief instrument for assessing treatment outcome. Addiction 1998; 93(12): 1857-67.

4. Gossop M, Marsden J, Stewart D. The UK national treatment outcome research study and its implications. Drug and Alcohol Review. 2000; (19): 5-7.

5 . Gossop M et al. The national treatment outcome research study (NTORS): 4-5 year follow-up results. Addiction 2003; 98(3): 291-303.

6 . Inciardi JA et al. An effective model of prison based treatment for drug involved offenders. Journal of Drug Issues 1997; 27(2):177-84.

7. Turnbull PJ, Mc Sweeney T. Drug Treatment in prison and aftercare: a literature review and results of a survey of European countries. Pompidou Group, Council of Europe; 2000.

8. Kothari G, Marsden J, Strang J. Opportunities and obstacles for effective treatment of drug users in the criminal justice system in England and Wales. Br J Criminology. of drug users in the criminal justice system in England and Wales. Br J Criminology.
$2002 ; 42: 412-32$.

9. Maguire $\mathrm{M}$, Raynor $\mathrm{P}$. The revival of throughcare: rhetoric and reality in automatic
conditional release. $\mathrm{Br}$ J Criminology $1997 ; 37(1)$. conditional release. Br J Criminology 1997; 37(1).

10. Burrows $\mathrm{J}$ et al. The nature and effectiveness of drugs throughcare for released prisoners. Research Findings No. 109, Home Office Research. Development and Statistics Directorate; London, 2000.

11. Hough M. Drugs misuse and the criminal justice system: a review of the literature. Drugs Prevention Initiative Paper15. London; Home Office; 1996.

12. Porporino FJ et al. An outcome evaluation of prison-based treatment programming for substance users. Substance Use and Misuse. 2002; 37(8-10):1047-77.

13. Lipton $S$ et al. The effects of therapeutic communities and milieu therapy on recidivism: meta-analytic findings from the correctional drug abuse treatment effectiveness (CDATE) study. In: McGuire J, editor. Offender rehabilitation and treatment: effective programmes and policies to reduce re-offending. Chichester: John
Wiley; 2002 .

14. Taxman FS and Bouffard JA. Assessing therapeutic integrity in modified therapeutic communities for drug-involved offenders. The Prison Journal 2002 June; 82:189-212 15. Ramsay M. Home Office, Development and Statistics directorate Research Study No. 267. London: Home Office; 2003.

16. Liese B.S and Franz RA. Treating substance use disorders with cognitive therapy: lessons learned and implications for the future. In Salkovskis PM., editor, Frontiers of cognitive therapy, London, Guilford Press; 1996.

17. Michael and Associates. Crime Pics II, Cardiff: Michael and Associates; 1994

18. DPP v. Finn [2000] IESC 75; [2001] 2 IR 25 (November 24, 2000). The Supreme Court 228/99.

19. Inciardi J. A. Drug treatment and criminal justice. London: Sage; 1993.

20. Dillon L. Drug use among prisoners; an exploratory study. Dublin; Drug Misuse Research Division; Health Research Board; 2001.

21. Pugh J. Introduction of a drug treatment case management system into the Irish Prison Service. Unpublished MSc thesis. Dublin, Trinity College; 2004. 